\title{
A C.ASE
}

\section{or \\ WOUND OF THE HEART.}

By J. FEATHerston, Ess.

COMMUNICATED BY

ASTLEY COOPER, EsQ.

Read April 24, 1810.

Richard hollidge, a private in the Northampton Regiment, being on sentry on Thursday night, at 10 o'clock, March 29th, with an unfixed bayonet in his hand, slipped down, and the bayonet entered his side between the sixth and seventh ribs, running directly upon the superior edge of the latter. He was some yards distant from the gate at which he was posted, and being challenged, returned to open it with the bayonet still remaining in the wound; he was incapable of withdrawing it himself, and the person coming in extracted it for him. I was called to him within five minutes of the accident; he was 
then in a state of syncope, the extremities cold, and his pulse scarcely perceptible. 'In about the space of a quarter of an hour he gradually revived, did not complain of any severe pain, and expressed, " that he believed he was more frightened than hurt." I examined the wound with much diligence, but could not trace its extent farther than one inch and a quarter, though it was evident the bayonet had penetrated two inches: the hemorrhage was very inconsiderable. His wound was dressed, he was conveyed to the military hospital, and put into bed; he was incapable of laying on his right side; but slept tolerably well. On visiting him the following morn. ing, March the 30th, he complained of lancinating pains extending from the wounded part across the chest, and of severe fugitive pains in. different parts of the abdomen, his pulse was quick and thready, and tongue white and dry: these symptoms led to a suspicion that the pleura costalis, at least, was wounded, though no opening could be ascertained extending into the cavity of the chest. Sixteen ounces of blood were taken from his arm, a solution of magnesia vitriolata administered, and fomentations applied to the abdomen. He was obliged to be supported in bed nearly in a sitting posture, as respiration became much impeded when perfectly horizontal : in this position he appeared to breathe with freedom. In the evening he expressed himself in 
every respect much relieved; his pulse was less quick, and had lost its thready sensation; tongue more moist; his medicine had operated moderately. On the following morning, March the 31st, I found he had passed a good night, his pulse was calm, and steady, scarcely quicker than natural, and the tongue quite moist; the lancinating pains had subsided, and he merely complained of a trifling pain in the wounded part: this was increased by a slight cough, with which he became affected only this morning, and which was unattended by any expectoration. His aperient draught was repeated, an emulsion ordered for his cough, and the antiphlogistic regimen strictly adhered to. Throughout the day he was walking about the ward, in very good spirits, quite jocular in his conversation with his fellow patients, and expressed himself to them, that "low diet would not do for him any longer." He retired to rest about 9 o'clock; and fell asleep; at 11 he got out of bed to the commode, had an evacuation by no means costive, said " he felt himself chilly, and a sensation that he should die," returned into bed, and expired immediately; making a period of 49 hours from his first receiving the wound.

I dissected his body the following morning, in the presence of two other surgeons. On opening the chest, the pleura was found slightly inflamed 
for some distance around the puncture, and an effusion of coagulable lymph, uniting a small portion of the lung to the wounded part: the lung however was quite uninjured. At least two quarts of blood were effused into the cavity of the chest; the pericardium was nearly. filled with blood, and had a puncture through it, extending three quarters of an inch into the muscular substance of the left ventricle, about two inches from its apex. A small coagulum of blood was formed at the edge of the wound through the pericardium.

Upon opening the left ventricle of the heart, the bayonet was found to have penetrated the substance of the ventricle, and to have cut one of the fleshy columns of the mitral valve.

On a review of this case, I conceive it very curious, that an organ like the heart, possessing such excessive irritability, a part to which the most interesting of our sympathies are referred, and which is in some degree influenced by the most trifling, should be so materially wounded, and yet the system take so little cognizance of the injury. Death, in this case, it was perfectly evident, was not produced from any alarm excited in the system by the wound, but occurred, as a secondary consequence, from the hemorrhage increasing to such an extent, as to interrupt the actions of the heart and lungs. That the he- 
morrhage proceeded chiefly from the heart, must be admitted; there was no symptom whatever, which indicated a wound of the lungs; none could be found on the most deliberate examination; and the intercostal artery was entirely free from injury. 